\title{
Plantas del herbario del Hermano Bianor en el Museo La Salle Colegio Paterna (Valencia, España)
}

\author{
Plants of the Brother Bianor herbarium in the \\ La Salle Paterna School Museum (Valencia, Spain)
}

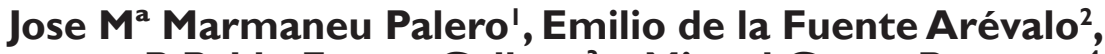 \\ P. Pablo Ferrer Gallego ${ }^{3}$ y Miguel Guara Requena ${ }^{4}$ \\ I. Centro Iberoamericano de la Biodiversidad CIBIO, \\ Universidad de Alicante, Carretera San Vicente del Raspeig s/n, \\ 03690 San Vicente del Raspeig, Alicante \\ josemarmaneu@gmail.com \\ 2. Colegio La Salle Paterna. Museo Hermano León. \\ C/San Luis Beltrán $n^{\circ} 8$ \\ 46980 Paterna, Valencia \\ emiliodelafuente@lasallevp.es \\ 3. Servicio de Vida Silvestre-CIEF \\ (Centro para la Investigación y Experimentación Forestal), \\ Generalitat Valenciana. Avda. Comarques del País Valencià, I I 4, \\ 46930 Quart de Poblet, Valencia \\ VAERSA. Avda. Cortes Valencianas, 20. 46015 Valencia \\ flora.cief@gva.es \\ 4. Departament de Biologia i Geologia, Facultat de CC. Biológiques, \\ Universitat de València. Avda. Dr. Moliner, s/n, 46100 Burjassot, València. \\ Miguel.Guara@uv.es
}

Recibido: Recibido: 2-octubre-20 I 7. Aceptado: I-febrero-20 I8. Publicado en formato electrónico: 6 de septiembre de 2018.

Palabras Clave: Hermano Bianor, Digitalización de pliegos de herbario, Documentación de colección clásica, Exsiccata, Herbario clásico, Islas Baleares, Museo La Salle de Paterna, Pliego de herbario, Sistemática.

Keys Words: Balearic Islands, Brother Bianor, Classical herbarium, Documentation of a classical collection, Exsiccate, Herbarium sheets digitization, Herbarium sheets, La Salle Museum in Paterna, Systematics.

RESUMEN

El presente estudio muestra la documentación, digitalización e informatización de la obra completa del Hermano Bianor contenida en el Museo La Salle de Paterna (Valencia, España). Esta colección clásica recoge parte de las recolecciones que el propio Bianor llevó a cabo durante su estancia en las Islas Baleares a principios del siglo XX. La colección consta de 12/4 pliegos de herbario recolectados entre los años 1905 y 1916 por diferentes localidades de la isla de Mallorca, especialmente en los municipios de Sóller y Palma de Mallorca. Además de una breve biografía del autor, se incluyen detalles sobre el origen de la colección, datos sobre los municipios donde se recolectaron las plantas, la frecuencia de recolección o la diversidad de familias.

ABSTRACT

The present study shows the documentation, digitization and computerization of the complete work of the Brother Bianor located in the Museo La Salle in Paterna, (Valencia, Spain). This classic collection includes part of Bianor works developed during his stay, in the early $20^{\text {th }}$ century, in the Balearic Islands, Spain. The collection bears 1214 herbarium sheets collected between 1905 to 1916 in different locations in the Majorca island, especially Sóller and Palma de Mallorca. Besides a brief biography of the author, this study also includes details on the origin of the collection, the localities where the plants were collected, frequency of the collection of plants or the families' diversity. 


\section{INTRODUCCIÓN}

Los primeros herbarios o herborizaciones históricas surgieron a lo largo de los siglos XVI-XVII como consecuencia directa de la profundización en el estudio de las plantas para su aplicación médica o alimenticia. Conocidos antiguamente como Hortus Siccus -jardines secos- los primeros herbarios permitieron una correcta conservación de las muestras vegetales lo que favoreció un rápido avance de la Botánica (PerALTA, 1992). Hoy en día, además de la vertiente docente y divulgativa, los herbarios constituyen una herramienta primordial para el estudio de los vegetales, en especial en campos como la taxonomía, la sistemática o la nomenclatura (SALGUEIRO, 1998; RouHAN et al., 2017).

Las colecciones históricas, sumado al valor intrínseco que representan como testigos de la historia, funcionan como fuente esencial de información, ya que proporcionan un material de comparación irreemplazable (Funk, 2003). En ciertas ocasiones, estas colecciones clásicas conservan los tipos nomenclaturales con los que se describieron las especies y por lo tanto constituyen un material de consulta obligatoria en los trabajos taxonómicos y de índole nomenclatural. Gracias a los herbarios históricos también es posible conocer detalles etnobotánicos sobre las plantas, como por ejemplo los usos tradicionales o propiedades medicinales (BROOKE, 2000).

Desde un punto de vista más genérico, estas colecciones también son útiles para conocer otros aspectos de las Ciencias Naturales, como por ejemplo ayudar a comprender y situar parte de la vida o actividad de un naturalista a través del fiel testimonio que su colección representa (IBÁÑEZ, 2006), realizar estudios en conjunto de la flora local de un territorio determinado, proporcionar información sobre el conjunto actual - histórico de las comunidades vegetales, distribución de las plantas -biogeografía-, etc. (DALTON, 2003).Asimismo, este tipo de colecciones también permite observar las variaciones o cambios ambientales, facilitando la identificación de los agentes promotores (Pyke \& Ehrlich, 20I0; FlanNerY, 20I2), o conocer la fenología de algún grupo taxonómico concreto (Peralta, 1992).

Aunque parezca que en la actualidad no queda espacio para las obras botánicas clásicas, la constante pérdida de biodiversidad (JENKINS, 2003) y la incesante antropización del medio natural (WALTHER et al., 2002), hacen cada vez más necesaria la información contenida en los herbarios clásicos o históricos. Es por ello que hoy en día una parte esencial de la documentación es la digitalización e informatización, ya que además de permitir una mejor conservación del material vegetal al evitar futuras manipulaciones -incluso una copia de seguridad en caso de pérdida o destrucción del material original-, se consiguen copias virtuales del material conservado capaces de ser compartidas y estudiadas por todo el mundo sin riesgo alguno de deterioro o destrucción. Esto supone una herramienta de colaboración entre diferentes comunidades científicas -o de aficionados- que en definitiva fomenta y hace gala de los valores cooperativos de la ciencia (SCHMIDT, 2007; FLANNERY, 20I2).

La digitalización también contribuye al progreso y desarrollo de la ciencia al interconectar investigadores de todo el mundo, permitiendo acortar los tiempos y recursos de desplazamientos o transporte (GÁlVEZ-PrADA et al., 20I4). No obstante, no hay que olvidar, tal y como apostillan VolLMAR et al. (20l0), que antes de digitalizar siempre se ha de priorizar la conservación de la colección y garantizar el rigor de las herramientas empleadas.

Este trabajo muestra exclusivamente la documentación, digitalización e informatización de la colección del Hermano Bianor almacenada en el Museo del Colegio La Salle de Paterna (Valencia, España).A través del análisis de los especímenes conservados se ha caracterizado la colección desde el punto de vista de los lugares más frecuentes de recolección -corología-; el periodo de mayor actividad del autor; las familias botánicas más representadas -riqueza-; la ecología de las muestras vegetales; la frecuencia de empleo de un determinado modelo de etiqueta y el peso de la docencia a la hora de la elección de los pliegos que conforman esta colección.

\section{I.I El Hermano Bianor}

El Hermano Bianor (I859-1920) de nacimiento Marie Émile Friquenon (Figura I), fue un importante botánico de principios del siglo $X X$ cuya contribución principal se desarrolló en torno a la flora balear. Nacido en Puxieux (Lorena, Francia), como muchos otros religiosos docentes tuvo que partir de su país natal cuando en 1904 se instauró la Ley Combes que prohibía la enseñanza a los religiosos (LALOUETTE, 2004). 


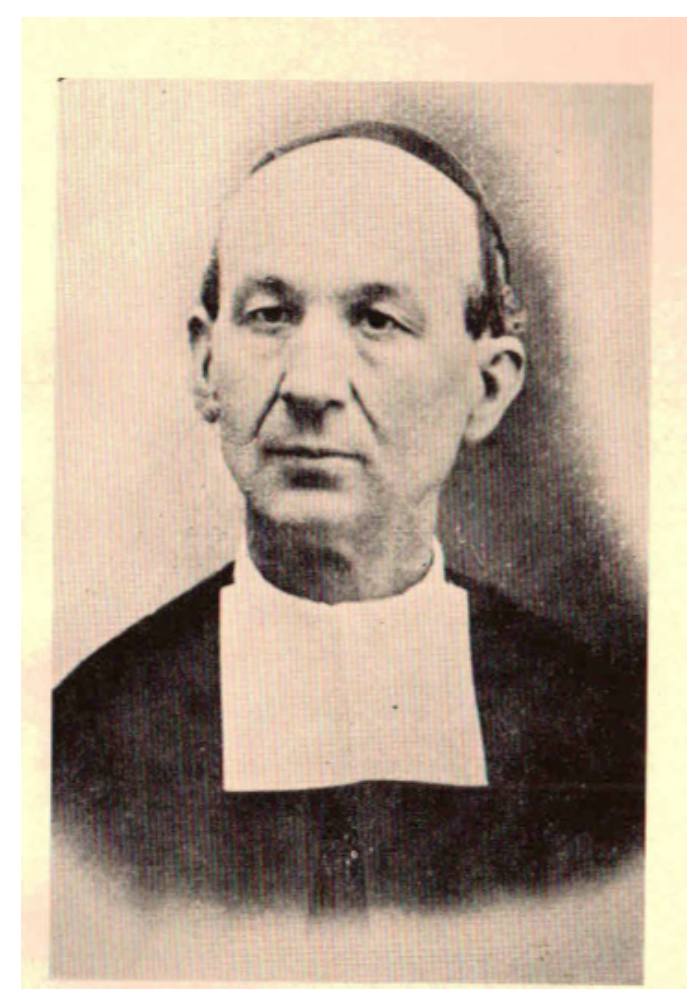

Figura I. Reproducción de la fotografía del Hermano Bianor conservada en el Hunt Botanical Library Carnegie-Mellon, University Pittsburgh Pennsylvania, de Estados Unidos. Picture of Brother Bianor preserved in the Hunt Botanical Library CarnegieMellon, University Pittsburgh Pennsylvania, United States (reproducida a partir de la imagen publicada por RuBí \& MALAGARRIGA, 197I).
Fue entonces cuando tras residir en diferentes lugares sus pasos se encaminaron hacia la isla de Mallorca. Allí, en colaboración muy estrecha con los botánicos más reputados del momento como Pius Font i Quer (I8881964), Carlos Pau Español (I857-1937) o Edward Loius Herman Knoche (1870-1945), pero en especial a través de Étienne Marcellin Granier-Blanc (186I-1937), más conocido como Hermano Sennen, estudió los materiales que componen la colección que ahora tratamos (RuBí \& MalagarRIGA, I 97I).

Como resumen, la obra balear de Bianor, 19051920, podemos dividirla tal y como refieren RUBí Y MALAGARRIGA (197I) en tres etapas: I) Sóller, 2) Mallorca y 3) Baleares. Estas etapas constituyen una ampliación progresiva del área de acción (recolección) reflejada en los diferentes herbarios que dejó Bianor.A día de hoy se conocen tres herbarios realizados por este autor, uno para cada colegio de la orden de los Hermanos de las Escuelas Cristianas asentado en las localidades en las que residió de manera estable, a saber: Sóller, Palma y Pont d'Inca (H. Miguel Pérez, com. pers. in litt., 20I6). También existen referencias de un cuarto herbario, el suyo propio y personal, que estuvo con él en sus aposentos de Pont d'Inca hasta el fin de sus días, pero que no ha transcendido a la actualidad al destruirse por completo tras la muerte de Bianor, por considerar que era riesgo de contagio de tuberculosis (Rubí \& Malagarriga, I97I).

Así, los herbarios que creó el H. Bianor hasta 1918 son: el del Museo La Salle de Palma, el del Museo La Salle de Pont d'Inca y el del Museo La Salle de Paterna, que corresponde con el herbario que realizó para el colegio La Salle de Santa María de Sóller. Los dos primeros fueron entregados a las instituciones mallorquinas cuando ambos museos cerraron y actualmente se encuentran en el Jardín Botánico de Sóller. Por su parte el Herbario del Museo La Salle de Paterna, que es el que hoy estudiamos, llegó del Museo La Salle de Palma, aproximadamente en 1962, donde estaba almacenado tras el cierre del colegio La Salle de Santa María de Sóller, por petición expresa del Hermano León, encargado del museo de Paterna $(\mathrm{H}$. Miguel Pérez, com. pers. in litt., 2016).

Además, es sabido que buena parte del material de estos herbarios fue repartido mediante la exsiccata Plantes d'Espagne por el H. Sennen a diferentes centros de todo el mundo. No obstante parte de la colección quedó en el museo del colegio La Salle Bonanova (Barcelona) donde Sennen trabajaba, encontrándose en la actualidad repartida entre el Jardí Botànic de Barcelona y propio colegio, que aún conserva 258 pliegos de Bianor (La Salle Bonanova, 2016).

\section{I.2 El Museo La Salle de Paterna}

El Museo La Salle del colegio de la orden homónima ubicado en Paterna (Valencia) fue fundado a lo largo del curso escolar 1953/I954 por el Hermano Fidel, director de la institución (Colegio La Salle Paterna, 2017a), con la finalidad de facilitar el estudio de las Ciencias Naturales a los alumnos del propio colegio (Figura 2). La llegada del Hermano León en 1960 (Colegio La Salle Paterna, 20I7b) propulsó la colección tanto en cantidad como en calidad, llegando prácticamente inalterada hasta nuestros días. Actualmente la colección del museo comprende una amplia representación del mundo natural, tanto de animales y vegetales como minerales, destacando por su calidad la gran colección de aves de todo el mundo, las muestras fósiles de incalculable valor - el propio herbario, con pliegos de más de un siglo de antigüedad y en excelente estado de conservación. En total el museo alberga cerca de 14.600 ejemplares todos ellos debidamente etiquetados y clasificados, figurando en la actualidad en el "Regis- 
tro de Colecciones, Proyectos y Bases de Datos de Biodiversidad en España" con el código CLS-MHLP (GBIF.ES Museo Hermano León, 20I6).

Por lo que respecta a la colección botánica (Figura 3), el museo alberga un herbario especial o histórico en el sentido que a este tipo de colecciones le otorgan BRIDSON \& FORMAN (1992). Dentro de la flora mediterránea, el herbario recoge bien representada especialmente la flora balear. Estos pliegos (Figura 4) que en origen fueron recolectados y elaborados por el propio Bianor para el Colegio La Salle Santa María de Sóller, fueron transportados al Colegio La Salle por petición del Hermano León desde el Museo La Salle de Palma -creado por el H. Emilio Castro- presumiblemente en 1962, cuando Santa María de Sóller cerró sus instalaciones $(\mathrm{H}$. Antonio Martín, com. pers. in litt., 20I6). La otra parte de la colección botánica del museo son materiales procedentes de pliegos duplicados o sobrantes del herbario del colegio La Salle Bonanova (Barcelona).

\section{Material y Métodos}

\section{I Material de estudio}

La colección botánica del Museo La Salle de Paterna se encuentra constituida por una serie de pliegos incluidos en 8 urnas o cajones -existen dos cajones más que se encuentran vacíos- ubicados en la primera vitrina situada a la izquierda de la entrada principal del museo. La vitrina está dividida en dos secciones, cada una de las cuales tiene unas dimensiones de $202 \times 84 \mathrm{~cm}$ alto y ancho, lo que en total supone $202 \times 168 \mathrm{~cm}$ (Figura 3). Interiormente cada vitrina se encuentra dividida en 5 baldas o estantes de cristal, más una superficie inferior. Cada anaquel mide $80 \times 48 \mathrm{~cm}$ largo y profundo, y soporta cada uno de los cajones o urnas que albergan la totalidad de los pliegos del herbario del museo.

Por lo que respecta a los cajones, estos presentan unas medidas de $30 \times 69,5 \times 47,5 \mathrm{~cm}$ alto, ancho $y$ profundo, con una apertura horizontal apoyada en dos bisagras en la parte frontal-inferior que deja al descubierto los diferentes paquetes que contiene. Además, la parte delantera de cristal contiene los siguientes elementos: una etiqueta de carácter logístico en el centro superior con el número de caja y los paquetes almacenados -en números romanosy sendas etiquetas en la parte inferior derecha e

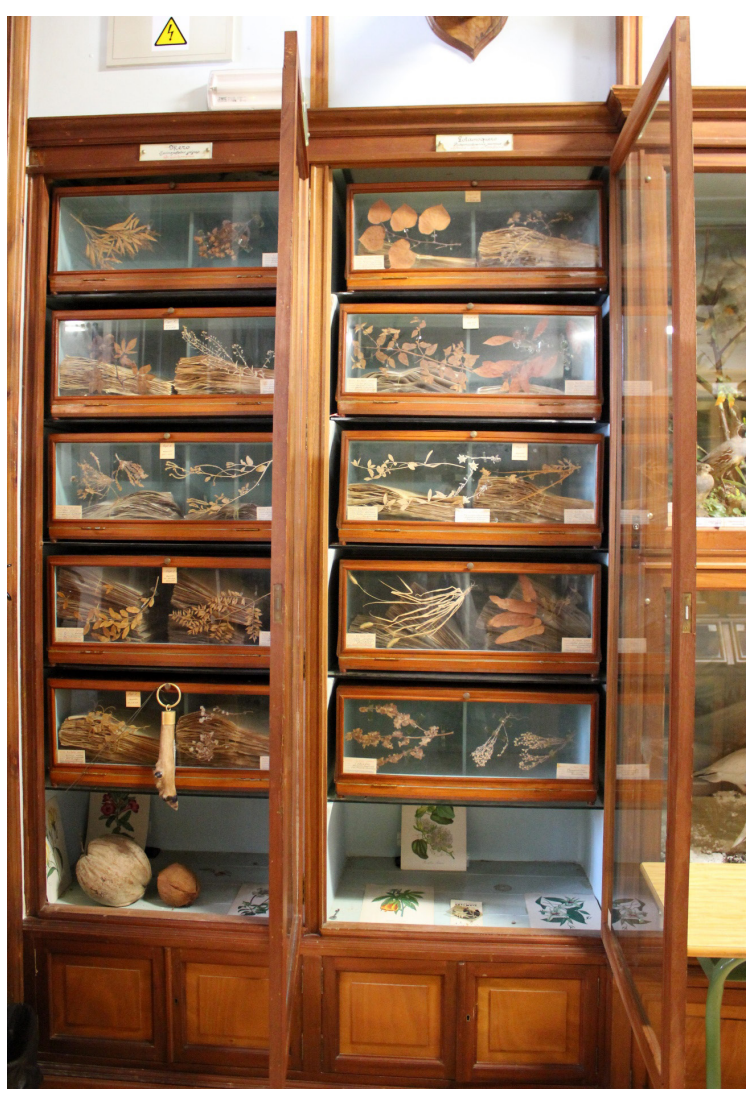

Figura 2. Interior del Museo La Salle en el Colegio La Salle de Paterna.

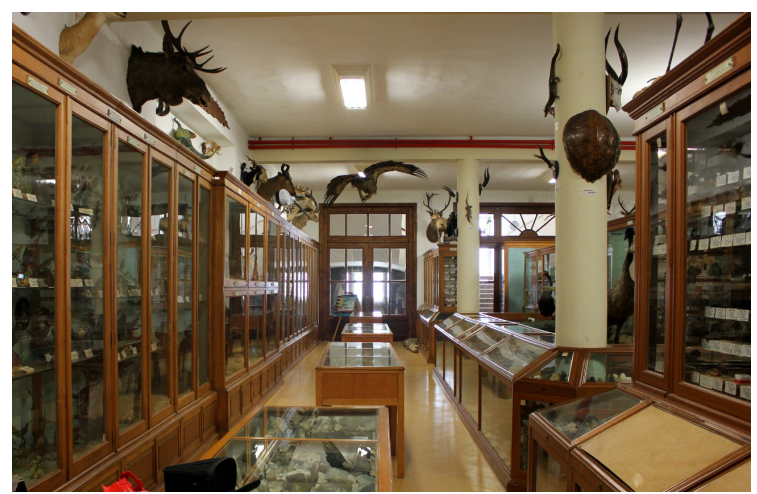

Figura 3. Imagen de la vitrina que alberga la totalidad de la colección botánica del Museo La Salle de Paterna (Valencia). izquierda, que aportan la información de los ejemplares expuestos y pegados en la cara interna del cristal con finalidad didáctica y visual.

En cuanto al orden de los cajones en la vitrina, el único patrón destacable lo comprende: cajones impares en la parte izquierda de la vitrina y pares en la derecha. De arriba a abajo y de izquierda a derecha, el orden es el que sigue: caja vacía, caja I, caja 5 , caja 7 y caja 3; caja 2, caja 6, caja 4, caja sin número (8) y caja vacía. Los espacios que resultan en el piso inferior están decorados con láminas y elementos vegetales ajenos a la colección. En el presente estudio se ha procedido exclusivamente al análisis de los cajones I-4, pertenecientes a la colección del $\mathrm{H}$. Bianor propiamente dicha.

Así pues, por lo que respecta al interior de los cajones I-4, estos están conformados cada uno por 4 paquetes de anchura variable en función de los pliegos contenidos. La distribución es secuencial hallándose en el cajón I, los paquetes I, II, III y IV; cajón 2:V, VI,VII y VIII; cajón 3: IX, X, XI y XII y cajón 4: XIII, XIV, XV y XVI. Cada paquete o legajo (Figura 4) es un conjunto de pliegos unidos mediante el anudamiento en cruz de un 


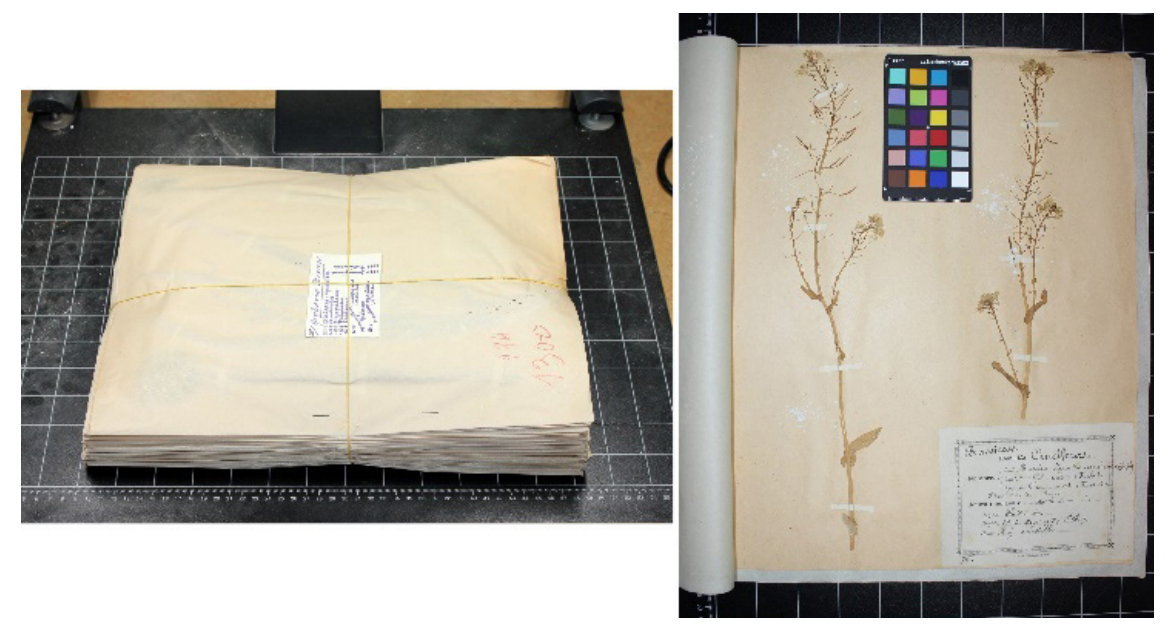

Figura 4. Izquierda, imagen de uno de los paquetes, y derecha, interior de un pliego. cordel amarillo y con una etiqueta donde se indica el número del paquete, la colección a la que pertenece y las familias botánicas que contiene.

Cada pliego de herbario está conformado por una lámina de papelcartón o cartulina de $37,5 \times 31 \mathrm{~cm}$ alto y ancho, donde se encuentra alojada la muestra vegetal acomodada mediante tiras rectangulares pegadas en sus extremos y la etiqueta con la información del pliego (Figura 4). La numeración manuscrita por el H. Bianor presente en estas etiquetas se recoge bajo el código C2. Para su adecuada conservación las muestras se encuentran espolvoreadas con un polvo blanquecino empleado como conservante tóxico. A su vez cada lámina está incluida dentro de una camisa de papel más fino de dimensiones ligeramente superiores $38,5 \times 32 \mathrm{~cm}$ alto y ancho, que la envuelve y a la cual está fijada mediante dos grapas en la parte media del lateral izquierdo.Además, cada camisa presenta en la cara frontal el número correspondiente a la ordenación propia del museo, representado por el código $\mathrm{Cl}$.

\subsection{Metodología empleada en la digitalización del material de herbario}

Para documentar la colección del $\mathrm{H}$. Bianor se ha utilizado principalmente la biografía de RuBí y MALAGARRIGA (I97I), extrayendo de ella la mayor parte de la información, así como las referencias epistolares (Bianor, 1910-1920). También se ha consultado la publicación de Bianor, Plantes de Mallorca (Bianor, 1917), además del catálogo del propio Museo La Salle de Paterna. Por último, también ha sido muy informativa la comunicación personal de varios Hermanos y personas cercanas a la vida y obra de Bianor (H. Jesús Comín, com. pers., 2016 ; H. Antonio Martín y H. Miguel Pérez, com. pers. in litt., 2016).

La digitalización de las muestras -fotografiado de los pliegos y las etiquetas- se ha llevado a cabo en las propias instalaciones del Museo La Salle ente los meses de marzo y junio de 20 I6. Para ello se ha utilizado un soporte para cámara Kaiser RTX con equipo de iluminación Kaiser RB 5000 DL. Todas las imágenes fotográficas se tomaron con una cámara Canon EOS 550D con objetivo EF-S/ 8-55mm f/3.5-5.6 IS II, utilizando el programa de exposición P.Además, en todas las imágenes de las muestras vegetales se incluyó un calibrador de color $x$-rite colorchecker classic mini.

Para los pliegos generales se realizaron dos fotografías: camisa y muestra vegetal -incluyendo la etiqueta-; mientras que para ciertos pliegos extraordinarios se tomaron más imágenes en detalle. Las imágenes generales de los pliegos se realizaron a una altura variable de entre los $44-46 \mathrm{~cm}$ de distancia y con una longitud focal de $18 \mathrm{~mm}$ a excepción de las fotografías de detalle, que fueron tomadas a una longitud focal de $35 \mathrm{~mm}$. Todas las imágenes se hicieron con el flash activado contribuyendo a la iluminación artificial aportada por la plataforma de trabajo además de la propia luz del museo. Posteriormente las fotografías se trataron con el programa de edición de imágenes Picasa en su $3^{a}$ versión desarrollado por Google. Los retoques más habituales consistieron en encuadres de la imagen, eliminación de bordes y ajustes del contraste -brillos, realces y sombras- empleado para corregir la exposición sin alterar el color.

Finalmente, en la fase de informatización se recopiló toda la información contenida en los pliegos en una base de datos utilizando el programa OpenOffice Calc. La información fue transcrita literalmente respetando al máximo el texto original. Pese a que Bianor no indicaba el recolector de las muestras vegetales con la abreviatura de Leg., se 
ha podido otorgar su autoría mediante la revisión de su caligrafía gracias al estudio de cartas manuscritas suyas expuestas en Rubí Y MalagarRIGA (197I).

\section{RESULTADOS}

El estudio de la colección del H. Bianor del Museo La Salle de Paterna revela la existencia de 1214 pliegos de herbario debidamente etiquetados, si bien, cuatro carecen de información taxonómica (familia, tribu, género, especie) y no se consideran en los cálculos posteriores. Estos se encuentran agrupados en 16 paquetes numerados del I al XVI y que a su vez están almacenados en 4 cajas -I, 2, 3 y 4-, hallándose por término medio 76 pliegos por paquete y 304 por caja. El número total de muestras estudiadas coincide con la numeración que aparece escrita en la camisa de los pliegos -denominada $\mathrm{Cl}$-, que a su vez concuerda con el número de pliegos recogidos en la base del catálogo del propio museo. Por contra, esta numeración de la camisa no coincide con la referencia original manuscrita de las etiquetas -a la que llamamos C2- que discontinuamente alcanza la cifra de $\mathrm{I} 6 \mathrm{I} \mathrm{I}$. El resto de los pliegos pertenecientes a las otras colecciones del museo, que no se consideran por ser ajenos a la colección del $\mathrm{H}$. Bianor y pendientes de digitalización, se ubican en: 598 de la colección Bonanova en las cajas 5 y 6, de principios del siglo XX, y 172 de la colección Comín-Malagarriga en las cajas 7 y 8 , de muestras recogidas en el año 1966.

El análisis de la diversidad revela un total de I 25 familias, 5 I 5 géneros y I I 24 especies, sin incluir rangos infraespecíficos (Tabla I). Las especies dicotiledóneas $(80,5 \%$ de las especies) son las mayormente representadas, mientras que las gimnospermas $(0,5 \%)$ las más escasas.

La colección del H. Bianor refleja de modo parcial la diversidad de la flora balear si se compara con los datos elaborados por RITA \& PAYERAS (2006). Las familias están representadas en su totalidad $\left(\chi^{2}=0,785|5, p=0| 4698,\right)$, pero existe una inflación significativa en el número de géne$\operatorname{ros}\left(\chi^{2}=0,00305, p<0,00 I\right)$ $y$ especies $\left(\chi^{2}<0,00001\right.$, $\mathrm{p}<0,00 \mathrm{I})$, respecto de la flora balear. La representación de las Gimnospermas es semejante a la recopilada para el conjunto del archipiélago $\left(\chi^{2}=0,60653\right.$, $p=0,26160)$, mientras que la representación de Pteridófitos $\left(\chi^{2}=0,00 \mathrm{IOI}, \mathrm{p}<0,0000 \mathrm{I}\right)$, Dicotiledóneas $\left(\chi^{2}=0,00101, p<\right.$ $0,0000 \mathrm{I})$ y Moncotiledóneas $\left(\chi^{2}\right.$ $<0,0000 \mathrm{I}, \mathrm{P}<0,0000 \mathrm{I})$, es significativamente menor.

Dentro de las familias, actualizadas según el criterio establecido por Flora ibérica (CASTROVIEJO, I986-20I2), destacan por su mayor representación de especies (Figura 5): Compositae con 125 especies, lo que supone un II, I\% del total, familia Leguminosae con II 3 spp. (I0,0\%), Gramineae con 86 spp. (7,6\%), Labiatae con 52 spp. (4,6\%), Cruciferae con 50 spp. (4,4\%), Umbelliferae con 4 I spp. (3,6\%), Caryophyllaceae con 40 spp. (3,5\%), Scrophulariaceae con 34 spp. (3,0\%), Ranunculaceae con 30 spp. (2,7\%), Rosaceae con 29 spp. (2,6\%), Liliaceae con 29 spp. (2,6\%), Euphorbiaceae con 25 spp. (2,2\%), Rubiaceae con 22 spp. $(2,0 \%)$ y, Orchidaceae y Cyperaceae con 20 spp. (I,8\%). El resto de
Tabla I. Número de pliegos de herbario por grupos taxonómicos y su distribución en familias, géneros y especies en la colección del H. Bianor del Museo La Salle de Paterna.

\begin{tabular}{ccccc} 
Grupo taxonómico & Pliegos & Familias & Géneros & Especies \\
\hline Pteridófitos & 23 & 12 & 15 & 23 \\
\hline Gimnospermas & 6 & 4 & 6 & 6 \\
\hline Dicotiledóneas & 978 & 90 & 399 & 904 \\
\hline Monocotiledóneas & 203 & 19 & 95 & 191 \\
\hline Total & 1210 & 125 & 515 & 1124 \\
\hline
\end{tabular}

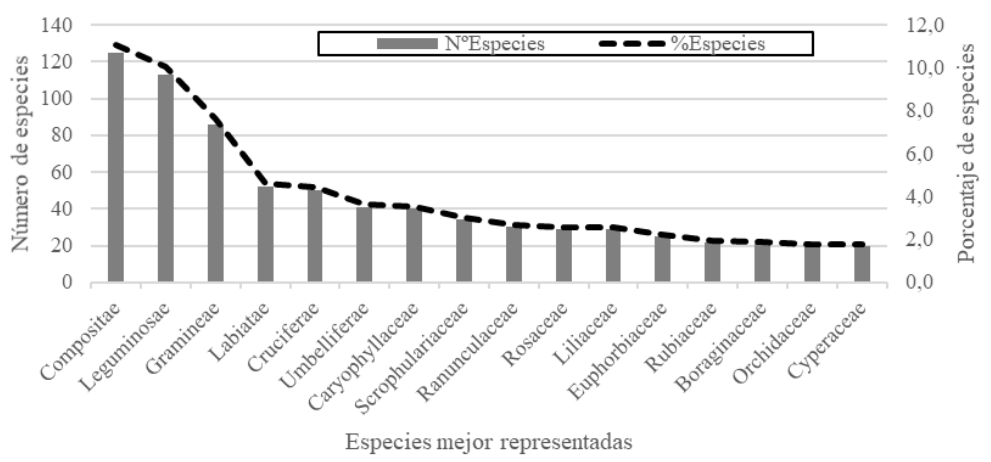

Figura 5. Diversidad de las familias de plantas vasculares con mayor representación de especies. 
Tabla 2. Ecología indicada en las etiquetas de los pliegos de la colección del H. Bianor del Museo La Salle de Paterna.

\begin{tabular}{cc} 
Ecología & $N^{\circ}$ de Pliegos \\
\hline Áreas montanas & 177 \\
\hline Campos & $27 \mathrm{I}$ \\
\hline Colinas & 202 \\
\hline Cultivos & 116 \\
\hline Forestal & 24 \\
\hline Huertos -plantas arvenses- & 42 \\
\hline Jardines & 16 \\
\hline Muros artificiales & 66 \\
\hline Otros & 14 \\
\hline Peñascos -plantas rupícolas- & 74 \\
\hline Plantas parásitas & 7 \\
\hline Sitios herbosos & 47 \\
\hline $\begin{array}{c}\text { Sitios húmedos -plan- } \\
\text { tas uliginosas- }\end{array}$ & 121 \\
\hline Torrentes & 20 \\
\hline Zonas acuáticas & 28 \\
\hline Zonas arenosas & 69 \\
\hline Zonas costeras \\
-no arenosas- & 24 \\
\hline Zonas pantanosas & 13 \\
\hline Zonas viarias & 200 \\
\hline
\end{tabular}

Tabla 3. Procedencia geográfica de las plantas de la colección del H. Bianor.

\begin{tabular}{ccr} 
Localidad & Pliegos & $\%$ \\
\hline Alaró & $\mathrm{I}$ & 0,08 \\
\hline Algaida & $\mathrm{I}$ & 0,08 \\
\hline Bañalbufar & 4 & 0,33 \\
\hline Binisalem & 2 & 0,16 \\
\hline Buñola & 26 & 2,14 \\
\hline Deyá & 6 & 0,49 \\
\hline Escorca & 46 & 3,79 \\
\hline Esporlas & 2 & 0,16 \\
\hline Fornalutx & 7 & 0,58 \\
\hline La Puebla & 29 & 2,39 \\
\hline Lluchmayor & $\mathrm{I}$ & 0,08 \\
\hline Marrachí & 18 & 1,48 \\
\hline Palma de Mallorca & 193 & 15,90 \\
\hline Pollensa & 4 & 0,33 \\
\hline Sóller & 652 & 53,71 \\
\hline Valldemosa & 7 & 0,58 \\
\hline Información insuficiente & 31 & 2,55 \\
\hline Sin procedencia & 178 & 14,66 \\
\hline Compartido & 6 & 0,49 \\
\hline Total & 1214 & 100 \\
\hline & &
\end{tabular}

las familias, cada una con menos de 20 especies, representan en su conjunto el $34,3 \%$ (387 especies) en contraposición al 65,4\% (737 especies) de las familias anteriormente citadas.

Por lo que respecta a la ecología de los pliegos estudiados (Tabla 2), los ambientes más representados son: campos, en el sentido amplio de la palabra (274 especies), colinas (202), zonas viarias (200), áreas montanas o montañosas (I77), sitios húmedos -plantas uliginosas- (I2I), cultivos -donde se incluyen tanto las especies cultivadas como las naturalizadas espontáneas- (I I6), peñascos -plantas rupícolas- (74), zonas arenosas -incluyendo arenales marítimos- (69), muros artificiales (66), sitios herbosos (47), huertos -como especies arvenses- (42), zonas acuáticas (28), zonas costeras -no arenosas- (24), forestales (24), torrentes (20), jardines ( I6), zonas pantanosas (I3), plantas parásitas (7) y 14 especies más en otros tipos de ambientes menos frecuentes como, escombros (I), grutas (I), ribazos (2), sitios áridos (3), sitios incultos (4), sitios secos (I) y valles (2). Por último, I 5 pliegos carecieron de referencia alguna a la ecología. Es necesario puntualizar que un mismo pliego puede recoger más de una categoría.

En cuanto a las localidades más frecuentes de herborización (Tabla 3), cabe destacar que más de la mitad de los pliegos, concretamente 652, es decir, un $53,71 \%$, fueron elaborados con material procedente del término municipal de Sóller. Dentro de este municipio las localidades o localizaciones más habituales fueron: barranco (24), Coll de Sóller (43) -de los cuales 20 pertenecen al puig del Teix-, huerta (22), puerto de Sóller (64), puig de l'Ofre (33), Sóller Este (59), Sóller Norte (45), Sóller Oeste (105), Sóller Sur (50) y torrente (I7).

El siguiente municipio más herborizado corresponde al de Palma de Mallorca, con 193, lo que representa un $15,9 \%$ del total, dentro del cual destacan los barrios de: Bellver (6), Coll d'en Rabassa (I6), El Molinar (19), Génova (6), Portopí (24), Son Rapiña (10) y Son Sardina (7). El resto de municipios por orden de frecuencia son: Escorca (46, de las cuales 31 pertenecen al puig Mayor), La Puebla (29, I3 de ellas pertenecientes a la albufera), Buñola (26, destacando las 7 de Raixa y 10 de la Sierra de Alfabia), Marrachí (I8, todas menos una de Pont d'Inca), Valldemosa y Fornalutx (con 7 cada una), Deyá (6), Pollensa y Bañalbufar (4 por municipio), Binisalem (2) y Alaró, Algaida, Esporlas y Lluchmayor con una única especie. Por último 3I pliegos contienen información insuficiente o muy genérica para poder ser ubicada dentro de un municipio concreto, y I 78 (I4,66\%) no presenta procedencia alguna, en contraposición de 6 pliegos con varios municipios compartidos.

Por su parte el estudio de las fechas de recolección indica que la primera planta herborizada data de 17 de enero de 1905, apenas 25 días después de la llegada del H. Bianor a Palma de Mallorca el 23 de diciembre de 1904. En el lado opuesto, la última planta incluida en esta colección data del 19 de octubre de 1916. Así, la distribución por años (Figura 6) muestra que el año más prolíico fue 1912, donde Bianor recolectó 275 pliegos, lo que supone el $22,7 \%$ de toda la colección. A continuación, se sitúa el año anterior, I9II, con 210 pliegos (17,3\%) seguido de 1910 con 179 (I4,7\%), 1913 con 
I 38 (I I,4\%), I 908 con I 3 | (I0,8\%), 1906 con $99(8,2 \%), 1909$ con 71 (5,8\%), 1905 con $45(3,7 \%), 1914$ con 26 (2,1\%), 1907 con 24 (2\%), 1916 con $3(0,2 \%)$ y, por último, 1915 con sólo una herborización $(0,1 \%)$. A estos datos hay que añadir la presencia de 2 pliegos sin fecha, y 7 donde sólo aparecen el día $y$ el mes.

Al realizar el mismo análisis por meses (Figura 7), se observa que el mes de mayor recolección es abril con 319 pliegos recogidos $(26,3 \%)$ seguido de mayo con 239 (19,7\%), junio con 177 (14,6\%), marzo con 123 (I0,1\%), agosto con $98(8,1 \%)$, julio con $82(6,7 \%)$, septiembre con 75 (6,2\%), febrero con $4 \mathrm{I}(3,4 \%)$, octubre con $22(\mathrm{I}, 8 \%)$, enero con II (0,9\%), noviembre con $9(0,7 \%)$ y, por último, diciembre con 7 pliegos $(0,6 \%)$. A lo que hay que sumar, 7 sin fecha y 2 donde solapan dos meses.

El estudio de los modelos de las etiquetas revela el empleo de 5 versiones diferentes de un mismo modelo de etiqueta. Así pues, variando simplemente en función del lugar de impresión se ha detectado que la versión de etiqueta más empleada ha sido la producida por Tip. de Calatayud y Pizá., con 535 etiquetas, casi la mitad de la colección (44,I\%). El segundo modelo más utilizado ha sido La Esperanza, Imp. de "Correo de Mallorca". Lonjeta I I., en 426 pliegos (35, I\%) seguido de Sóller - Imp. de «La sinceridad». en 179 pliegos (I4,7\%), Tip de A HOMAR en 72 pliegos $(5,9 \%)$ y Tip. de S. Pizá.- Sto. Cristo, 20 en sólo una etiqueta (0, I\%).

Complementariamente, el $50,5 \%$ de los pliegos (6I3) presentan anotaciones sobre el uso de la planta en la etiqueta, mientras que 60 I pliegos (49,5\%) no presentan este tipo de anotaciones.

\section{I Pliegos destacados}

De entre todos los pliegos destacamos aquellos que contienen muestras de plantas que fueron dedicadas por sus coetáneos Knoche, Pau y Sennen a Bianor, en reconocimiento a su labor recolectora. Todos los casos corresponden con las transcripciones literales de las etiquetas originales de los pliegos, los cuales demuestran tanto la rapidez con que Bianor adoptaba los cambios nomenclaturales incorporándolos en cuanto tenía noticia, como la importancia que el material de Bianor tuvo en una parte de las exsiccata repartida por Sennen en el primer cuarto del siglo XX.

3.I.I. I43/I68 (bis) Frankenia bianorii (hirsuta x pulverulenta) (Sennen et Pau); Frankeniaceas. “de Bianor; Frankénia”'; 20 á 60cm; Sitios arenosos; Portopí, Palma; 17 de abril, 19|3. [I-II]. (Figura 8).

El nombre "Frankenia bianorii" Sennen \& Pau in Bianor, Butll. Inst. Catalana Hist. Nat. 17: I34 (1917) es un nomen nudum y por tanto inválido, ya que en el trabajo original donde se publica esta "combinación" solo se menciona lo siguiente:"I3. Frankenia Bianorii, Sennen et Pau. Chemins, Liex sablonneux, à Portopí. Frankenia hirsuta $\times$ 


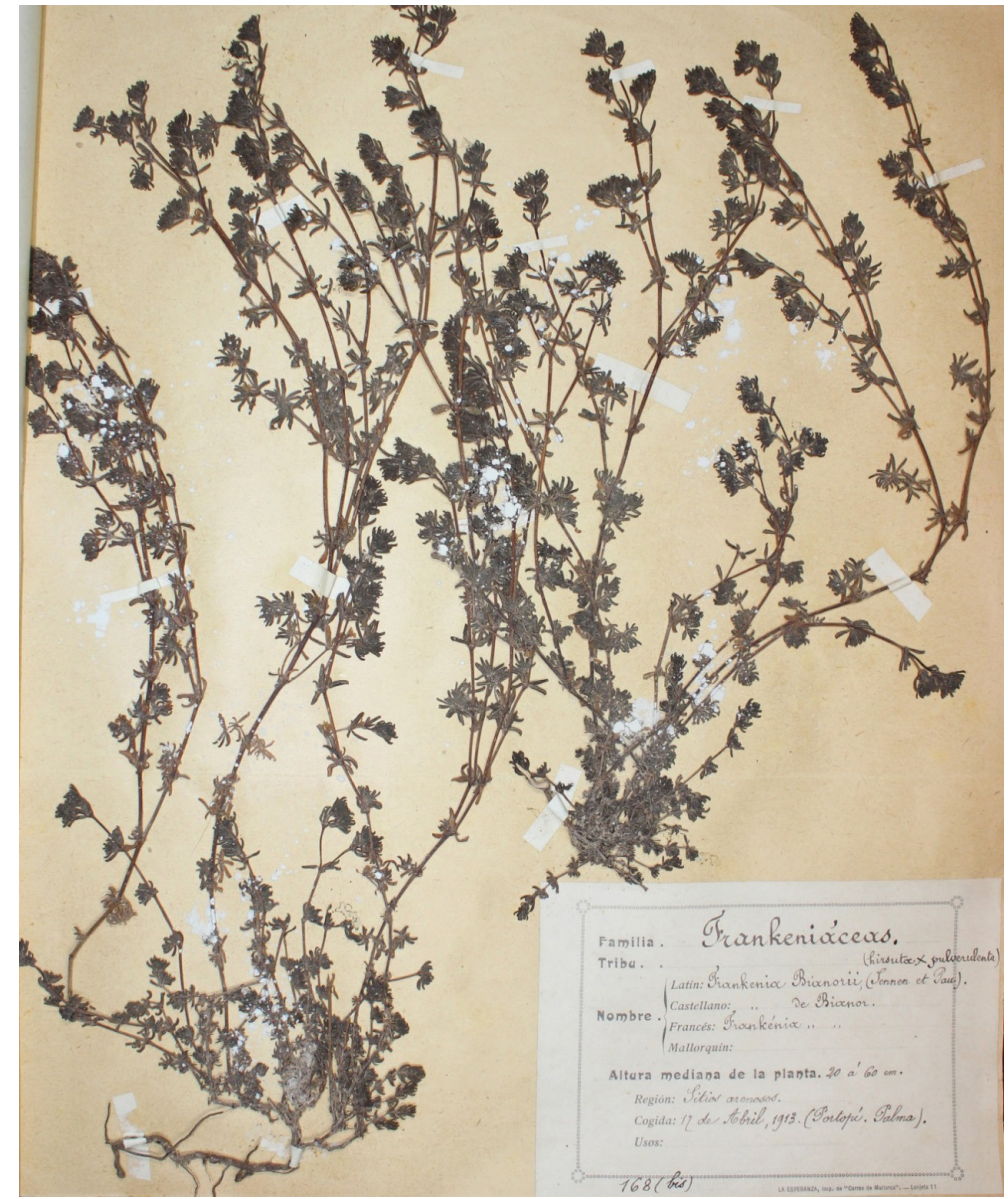

Figura 8. Frankenia bianorii (hirsuta $\times$ pulverulenta) Sennen et Pau, I43/I68 (bis) $[\mathrm{I}-\mathrm{II}]$.

pulverulenta", pero sin acompañar la propuesta de alguna descripción o diagnosis (véase BIANOR, I9I7: 134). Este nombre ha sido incluido dentro de la sinonimia de F. composita Pau \& Sennen in Font Quer, Iter Marroc. 1927, n. 392 (1928), in sched., pro hybrid. (véase: http:// www.floraiberica.es/PHP/cientificos2.php?gen $=$ Frankenia\&espe $=$ co mposita\&infrank = \&infra = \&auta bre $=$ Pau+\%26+Font + Quer+in+Fo nt+Quer\&familia=Frankeniaceae). Los datos indicados por BIANOR (1917: 134) corresponden con lo que aparece anotado en la etiqueta del pliego que se conserva en el Herbario La Salle de Paterna. Posteriormente, KNOCHE (1922: 191) publica una combinación y estatus nuevo "Frankenia hirsuta f. bianorii" (Sennen \& Pau), Knoche, Fl. Balear. 2: I9I (1922), propuesta que resulta asimismo inválida al estar basada en un nombre inválido.

3.I.2. 453/60I (bis) Ligusticum bianorii (Sennen et Pau); Umbelliferas, Seselineas. Apio montano de Bianor; Livèche de Bianor; 30 á $50 \mathrm{~cm}$; Montañas; Puig Mayor 1450m Norte; 10 de agosto, I9I0. [2-VII].

Ejemplares recolectados por Bianor en:"Baleares: Soller, uniquement dans les rochers" y distribuidos en una exsiccata de Sennen Planes d'Espagne 1912: n. 3945 (1912-1913) corresponden en realidad a Laserpitium gallicum subsp. majoricum Romo, Fl. Silvestre Baleares: 196 (I994) [holotipo: BC 24256, Coma de N’Arbona (Sóller), peñascos, leg. Rodríguez, 16 junio I877]. En el herbario de Bianor del Museo de La Salle de Paterna se conserva un material recolectado en 1910 en el Puig Mayor, y corresponde a la misma planta distribuida en la exsiccata de Sennen a partir del material recolectado por Bianor. Algunos autores han considerado que Ligusticum bianorii es sinónimo de L. huteri Porta (véase LeUTE, 1970: 476). Por otro lado, BIANOR ( 1917: I36) indicó una referencia para esta planta:"38. Ligusticum Huteri, Porta et Rigo, Dans le Barranc qui descend du Puig Major, partie Nord, pres des glacieres, I,400 m.", refiriéndose sin duda al material de herbario que se trata en este trabajo, pero sin hacer mención en su publicación al nombre Ligusticum bianorii, ya que éste no llegó a ser nunca efectivamente publicado.

3.I.3. 582/768 (bis) Filago bianorii (Sennen); Synanthereas - Corimbiferas, Gnaphalieas. Algodonosa de Bianor; Cotonnière; 5 á $15 \mathrm{~cm}$; Sitios arenosos. Caminos; Molinar, Palma; 29 de marzo, I9I0. [2-VIII]. (Figura 9).

Nombre actual vigente: Filago congesta Guss. ex DC., Prodr. 6: 248 (I838).

Esta especie fue válidamente publicada por Sennen y Pau en un trabajo firmado por SenNen (I9I3: 42): Filago bianorii Sennen \& Pau in Sennen, Bull. Géogr. Bot. 23: 42 (1913), en el que se indica como localidad clásica:"Baléares: sables maritimes du Molinar, près Palma” y como autor de la recolección:“(F. Bianor)”, y como número de la exsiccata por la que se repartió material original el "I 26I" (véase: https://www.biodiversitylibrary.org/item/23040\#page/54/mode/l up). Esta planta fue posteriormente indicada por BIANOR (1917: I37) de la siguiente manera: "Filago Bianorii, Sennen et Pau. Chemins et lieux incultes. Palma: remparts, Molinar... Sóller: chemins; Buñola: voie ferrée...”, 
pero sin incluir una diagnosis o descripción. WAGENITZ (1966) indicó dos muestras conservadas en el herbario LD y $M$ como material original de F. bianorii, pero sin elegir ninguna de ellas como lectotipo (véase ANDRÉs-SÁNCHEZ et al., 2016: 286). El lectotipo de este nombre fue designado por Rosselló \& SÁEZ (2000: 30) "Type material: Baléares: Sables maritimes de Molinar à Palma, VII- I 9 I I, Bianor, PI. d'Espagne-F. Sennen n I 26 I (BC 3 /263)", con la indicación de que el lectotipo es el ejemplar situado en medio:"“(middle specimen)". Esta tipificación es efectiva $y$ debe seguirse, aunque no hay motivo alguno por la que se deba seleccionar una parte del espécimen como tipo, pues todas las partes (plantas y/o fragmentos) que componen el pliego BC 3 I263, pertenecen a la misma especie y proceden de una única recolección, por lo que son un único espécimen según el Art. 8 del ICN (véase McNeILL et al., 2012). Recientemente, ANDRÉS-SÁNCHEZ et al., 20l6: 286) designan como lectotipo de F. bianorii el espécimen BC 874215 , también recolectado por Bianor en "Sables maritimes de Molinar à Palma" y distribuido en la exsiccata de Sennen, pero esta designación resulta superflua e inefectiva. Hemos localizado varios duplicados

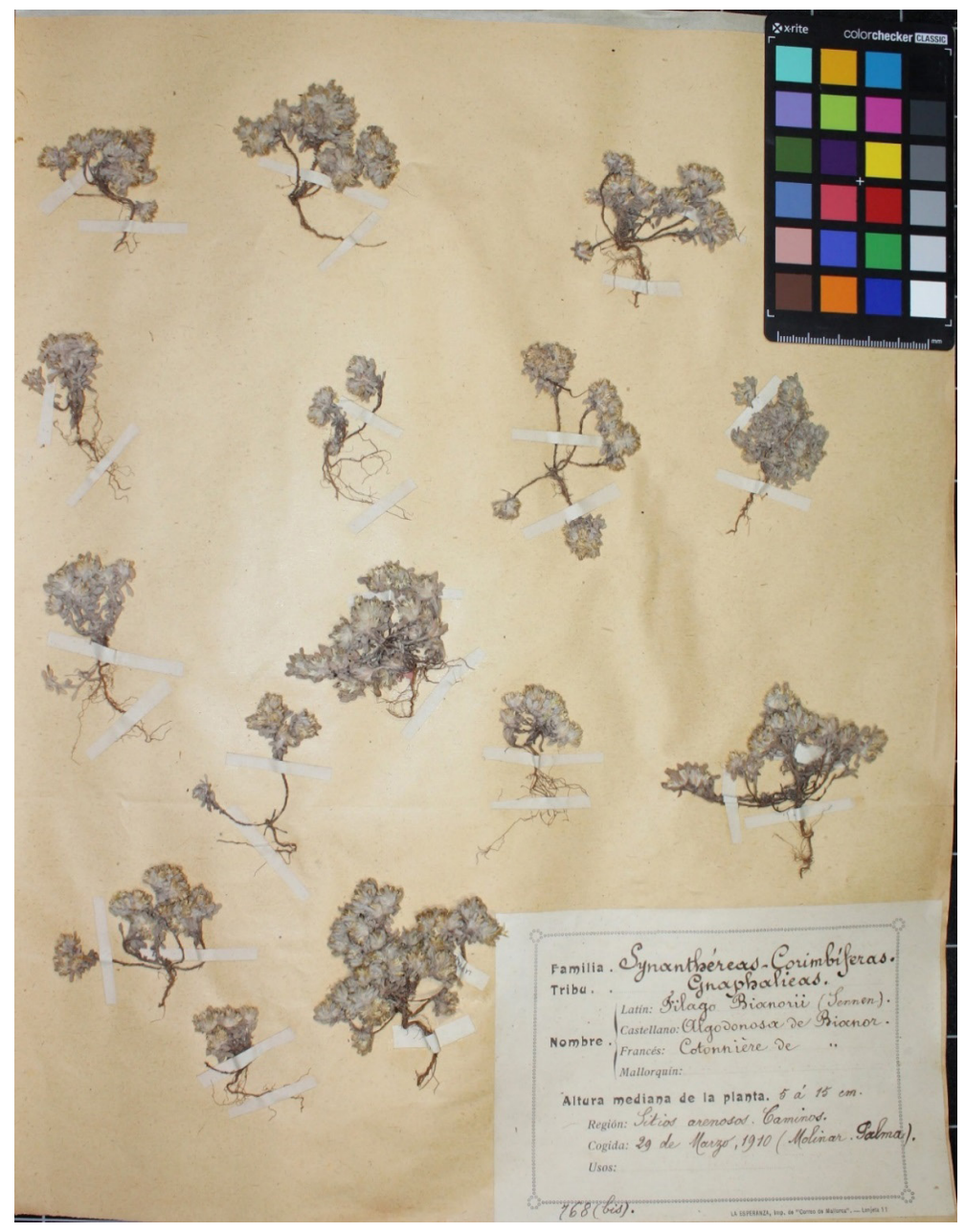

Figura 9. Filago bianorii Sennen, 582/768 (bis) [2-VIII]. Isolectotipo. de esta recolección en los siguientes herbarios: FR (código de barras FR003 I626), JE (código de barras JE000 I 7292), LD (código de barras LDI019588), M (códigos de barras M00298I8, M0029819) y JE (código de barras JE000I729I), especímenes que deben considerarse como isolectotipos. El material conservado en el herbario personal de Bianor en el Museo de La Salle de Paterna lleva anotado como fecha de recolección "29 de marzo de 1910", por lo que consideramos que forma parte del material original, y debe ser considerado como un duplicado del lectotipo, y por tanto, un isolectotipo, ya que la fecha que aparece en las etiquetas que tienen los pliegos repartidos en la exsiccata de Sennen Plantes d'Espagne con el número I26I, es la que indicara Sennen a partir del material enviado por Bianor, y no la fecha de recolección del material por parte de Bianor, por lo que, tanto el material lectotipo, como todos sus duplicados fueron recolectados por Bianor en una única fecha. En la actualidad es considerado un sinónimo de F. congesta Guss. ex DC. (Rosselló \& SÁEZ, 2000).

3.I.4. 773/I003 Linaria rubrifolia var. bianorii (D.C.) Knoche; Escrofulariaceas.; Linaire à feuilles rouges; 4 á I2cm; Sitios pedregosos; Canteras - Coll d’en Rabassa; 08 de mayo, 1913. [3-XI]. (Figura 10).

Nombre actual vigente: Chaenorhinum rubrifolium (Robill. \& Castagne ex DC.) Fourr. in Ann. Soc. Linn. Lyon ser. 2 I7: I 27 (1869).

El nombre "Linaria rubrifolia var. bianorii" Knoche in Bianor, Butll. Inst. Catalana Hist. Nat. I7: 138 (1917) es un nomen nudum y por tanto inválido, al ser publicado sin descripción y/o diagnosis validadora. En el trabajo de Bianor (1917: 134) tan solo se indica lo siguiente: "68. Linaria rubrifolia, D. C. Var. Bianorii, Knoche. Carrières de Coll d'en Rabassa.'. Sin embargo, años más tarde esta planta fue descrita por Knoche (I922: 382) como Chaenorhinum rubrifolium var. bianorii Knoche, Fl. Balear. 2: 382 (I922). Este 


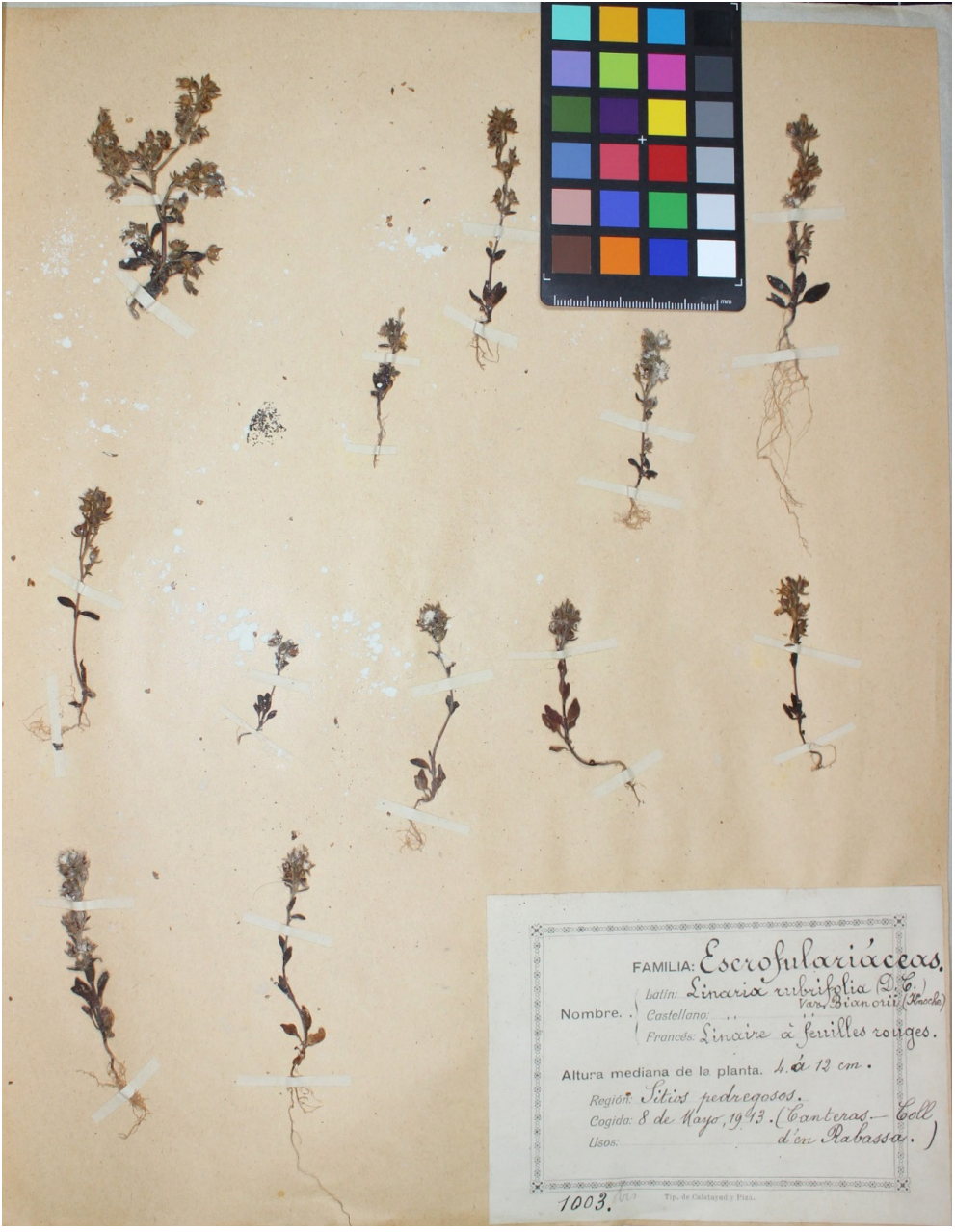

Figura 10. Linaria rubrifolia var. bianorii (D.C.) Knoche, 773/I003 [3-XI]. Isolectotipo. nombre ha sufrido a lo largo del tiempo diferentes recombinaciones y cambios de estatus taxonómico (como, por ejemplo: Linaria rubrifolia var. bianorii (Knoche) Maire in Bull. Soc. Hist. Nat. Afrique N. 3I: I I0 (I940); Chaenorhinum rubrifolium f. bianorii (Knoche) R. Fern. in Bot. J. Linn. Soc. 64: 226 (I97I); Chaenorhinum rubrifolium subsp. bianorii (Knoche) Malag., Subsp. Variac. Geogr. 18 (1973); Linaria rubrifolia subsp. bianorii (Knoche) O. Bolòs \& Vigo, Biogeogr. Baleares ed. 2209 ( I978), comb. inval.; Linaria rubrifolia f. bianorii (Knoche) O. Bolòs \& Vigo in Collect. Bot. (Barcelona) 14: 97 (1983)] y en la actualidad se considera sinónimo heterotípico de Chaenorhinum rubrifolium (Robill. \& Castagne ex DC.) Fourr. in Ann. Soc. Linn. Lyon ser. 2 I7: I 27 (I869) subsp. rubrifolium. Knoche publicó en su protólogo la siguiente indicación locotípica: "[...] abondant aux environs des carrières du Col d'en Rebassa (Torre d'en Pau) (Frère Bianor)". El espécimen lectotipo de este nombre fue designado por Benedí (1991: 74) a partir de un material conservado en el herbario MPU-Knoche (el lectotipo es el material que contiene el pliego que incluye cinco ejemplares en flor $y$ fruto, ya que en el herbario MPUKnoche existe otro pliego con material de Bianor, que es isolectotipo). El pliego que se conserva en el herbario del Museo de La Salle de Paterna debe ser considerado, por tanto, como duplicado del material lectotipo, y por consiguiente isolectotipo.

3. I.5. 869/I I 28 (ter) Statice - var. bianorii -; Plumbaginaceas. Estatice; Statice; 25 á 45cm; Orillas del mar; Portopí, bahía de Palma; 14 de agosto, I9I2. [3-XII].

Nombre actual vigente: Limonium bianorii (Sennen \& Pau) Erben in Mitt. Bot. Staatssamml. München 28: 350 (1989).

El nombre "Satice duriuscula var. bianorii" Sennen \& Pau fue referenciado por Bianor (1917: 140), donde se indica lo siguiente:"88. Statice duriuscula, Gir., Var. Bianorii, Sen et Pau. Rochers, au bord de la mer, chemin du grand phare. Sóller". Anteriormente, esta especie había sido válidamente publicada por SENNEN (I913: 47), como Statice bianorii Sennen \& Pau in Bull. Géogr. Bot. 23: 47 (1913), indicando como localidad típica "Báleares: Rochers des bords de la mer, près Soller", en cuyo protólogo aparece una amplia descripción de la planta y una localidad atribuida a una recolección de Bianor: "I097. Statice Bianorii Sen. et Pau, vel S. duriuscula Gir. var. eor. / Tiges plus ramifiées, à premier entre-noeud court ou très curt; rameaux plus grêles: épillets également plus grêles et plus courts 2-3 flores; partie campanulée du calice beaucoup plus évasée; feuilles radicales très nombreuses, à limbe graduellement atténué, et trèsverruqueuses. / Hab. - Baléares: Rochers des bords de la mer, près Soller (Fre. Bianor).”. Posteriormente, Sennen (1936: 3I) publicó una combinación y estatus nuevo para este nombre, repitiendo la propuesta de Bianor (1917: 140): S. duriuscula var. Bianoris (Sennen \& Pau) Sennen \& Pau in Sennen, Bol. Soc. Ibér. Ci. Nat. 35: 3 I (1936), y posteriormente Malagarriga (in RuBí \& Malagarriga, I97I: I37) consideró asimismo este rango taxonómico, pero dentro del género Limonium, a través de una propuesta inválida, como: L. duriusculum var. bianorii 
(Sennen \& Pau) Malag., H. Bianor Educador Botánico Baleares: I 37 (I97I), algo que posteriormente enmendaría al elevar el rango a subespecie en 1973: L. duriusculum var. bianorii (Sennen \& Pau) Malag., Subsp.Var. Geogr.: I 3 (1973). No obstante, con la revisión del género Limonium para la flora ibérica, ERBEN (1993) propuso la planta con el rango de especie: Limonium bianorii (Sennen \& Pau) Erben in Mitt. Bot. Staatssamml. München 28: 350 ( 1989) (véase ERBEN, 1993: I0I). El material tipo del nombre Statice bianorii (basiónimo de L. bianorii) se conserva en varios herbarios, ERBEN (I989) señaló como holotipo un espécimen conservado en BC, designación corregida aquí a lectotipo (Art. 9.9 del ICN). Hemos encontrado duplicados de la exsiccata de Sennen repartidos con el número " 1097" en los siguientes herbarios:JE (códigos de barras JE000 I I 777, JE000 I I 776 y JE000 I I775), M (código de barras M0I73960), FR (código de barras FR0038498) (véase: https://plants.jstor.org/search?filter=name\&so=ps_group_by_genus_species+as c\&Query=limonium+bianorii) y MA-0 I-00091972 (http://colecciones.rjb.csic.es/\#card. php?id_name $=56834 /$ ). No obstante, todo este material tipo (lectotipo e isolectotipo) lleva como fecha "I9I0-IX" y localidad "Baléares: Rochers des bords de la mer, près Sóller", mientras que el material que se conserva en La Salle de Paterna fue recolectado el 14 de agosto de 1912 y en la localidad de:"Orillas del mar; Portopí, bahía de Palma", por lo que no es material duplicado del empleado por Sennen y Pau para describir en 1913 su Statice bianorii.

3.I.6 924/I 202 (bis) Aristolochia bianorii (Sennen et Pau); Aristoloquiaceas. Aristoloquia de Bianor; Aristoloche de "; 25 á $60 \mathrm{~cm}$; Sitios pedregosos. Montañas; Sóller, Muleta; 16 de mayo, I9I0. [4-XIII]. (Figura II).

Nombre actual vigente: Aristolochia bianorii Sennen \& Pau in Butll. Inst. Catalana Hist. Nat. I I: 19 (I9II)

Especie descrita en por PAU (191 I: 19), en cuyo protólogo se indica lo siguiente: "I8.- ARISTOLOCHIA BIANORII Sennen et Pau. Radix fibrosalridico capillaribus, folia ovata obtusa, floribus axilaribus solitariis $35-0 \mathrm{~cm}$., lígula tubo longitudine.", añadiendo además "A. Pistolochiae affinis, sed distinctissima.". En la actualidad Aristolochia bianorii Sennen \& Pau in Butll. Inst. Catalana Hist. Nat. II: 19 (I9II) se considera como una buena especie, endémica de las Islas Baleares (CASTroviejo, 1986: 205). La indicación locotípica que viene reconociéndose es la siguiente:“... recogidas en las cercanías de Sóller, ó en su jurisdicción, por el hermano Bianor" que es la que aparece de manera genérica en el apartado introductorio del trabajo de PAU (|9||: |6). Desde el punto de vista nomenclatural, NARDI (1984) designó como el lectotipo de este nombre un espécimen conservado en el herbario MA. En el herbario de Pau, conservado en MA, aparece un pliego (MA 27358) que pertenece a la exsiccata de Sennen Plantes d'Espagne, material que fue recolectado por Bianor y distribuido por Sennen en la citada exsiccata, con el número 1284. En esta exsiccata aparece como localidad "Baléares: Montagnes à Sóller - 50 à 1000 m." y fecha "I9II - Vl". Hemos localizado material duplicado en diferentes herbarios: BM (código de barras BM0006|3052), M (códigos de barras M0274562 y M027456I), MPU (código de barras MPU0 18747), DAO (código de barras DAO000466754), JBAG (código de barras JBAG-Lainz2045), materiales que deben considerarse, por tanto, como isolectotipos. Por otra parte, el pliego conservado en el Herbario La Salle de Paterna, aunque coincidente en la localidad "Sitios pedregosos. Montañas; Sóller, Muleta" tiene anotada otra fecha de recolección "I6 de mayo, 1910". En este sentido, es necesario conocer si la exsiccata de Sennen fue repartida a partir de la recolección inicial realizada por BIANOR en 1910, aunque fuera repartida con fecha de junio de 191I, por lo que el espécimen conservado en el herbario La Salle de Paterna sería un isolectotipo; o, por el contrario, si Bianor hizo dos recolecciones y fue la de I9II la única repartida por Sennen. Posteriormente, SENNEN (1913:49) publicó con el número de su exsiccata "I284" lo siguiente:"I284. Aristolochia Bianorii Sen. et Pau, Bol. Soc. cat. Hist. Nat. 191 I. / La racine de cette plante est petite et napiforme, mais non fibreuse fasciculée, comme le croyant le $\mathrm{D}^{r}$ Pau lors la description. / Hab. - Baléares: Montagnes de Sóller, entre 50 et 1.000 m. (Fre. Bianor).”. Por tanto, en este trabajo de Sennen de 1913 tampoco se indica la fecha de recolección del material por parte de Bianor, y el vínculo que establece el número de la exsiccata "I284" con el material de 


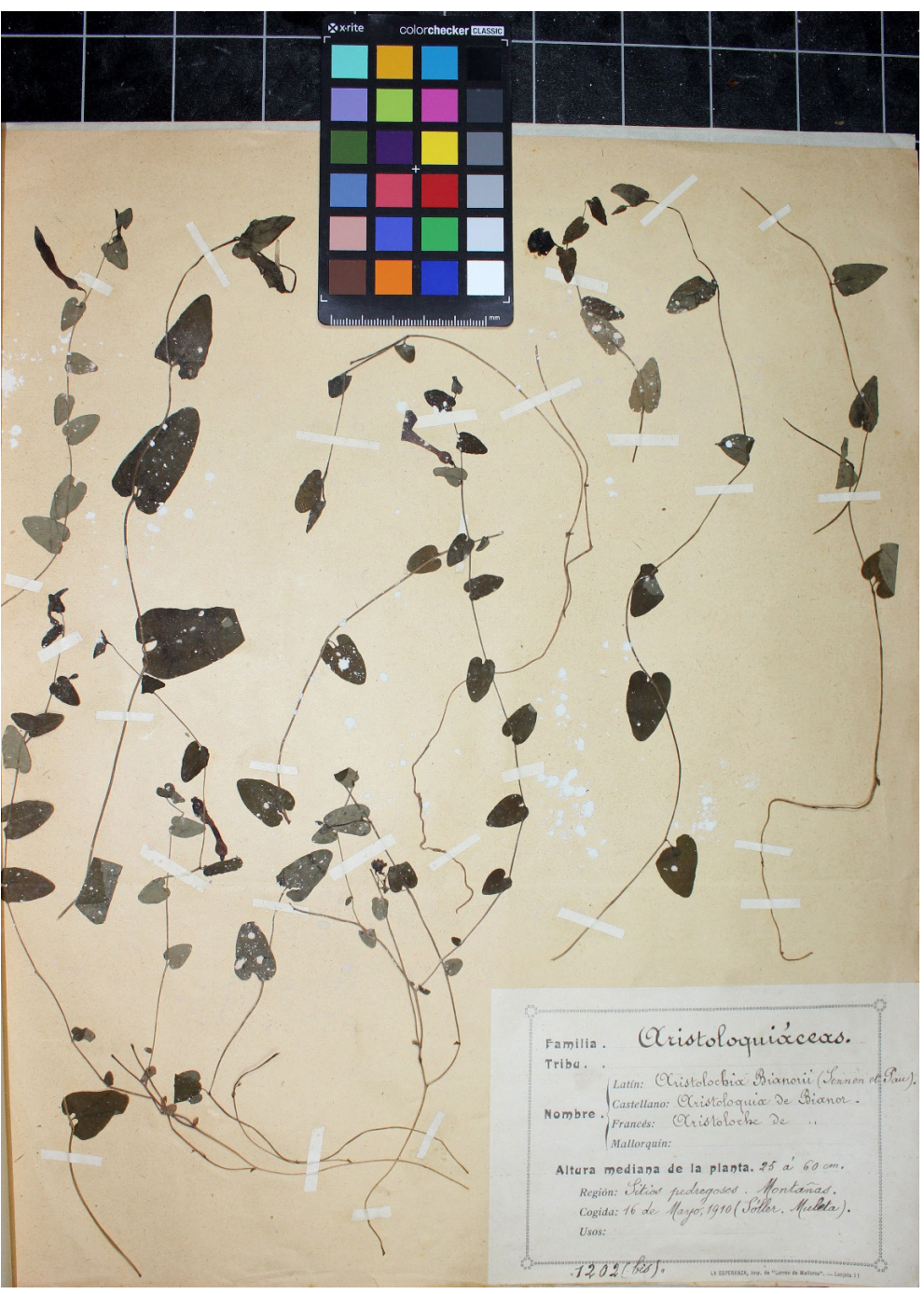

Figura I I. Aristolochia bianorii Sennen et Pau, 924/I 202 (bis) [4-XIII]. Isolectotipo/Isolectotype. herbario fija la fecha del material en junio de 1911 , aunque en nuestra opinión todo el material repartido por Sennen fue recolectado por Bianor el 16 de mayo de 1910.

\section{DISCUSIÓN Y CONCLUSIONES}

Gracias a la labor realizada a lo largo de este trabajo, los 1214 pliegos de herbario que componen la colección del Hermano Bianor, dos tercios del material del herbario del Museo La Salle de Paterna, se encuentran digitalizados $\mathrm{e}$ informatizados para su uso futuro. El estudio de este herbario revela que las 4 primeras cajas - I a 4- corresponden a material recolectado y herborizado por el $\mathrm{H}$. Bianor, entre 1905 y 1916 en diferentes municipios y localidades de la isla de Mallorca, Islas Baleares. El resto del herbario, en fase de estudio, lo componen 598 pliegos de la colección Bonanova -cajas 5 y 6- y 172 pliegos de la colección Comín-Malagarriga de 1966 -cajas 7 y 8-.

Por otra parte, la búsqueda y síntesis de documentación sobre el origen de la colección del $\mathrm{H}$. Bianor, aportando muchos datos novedosos consecuencia de la investigación y la información obtenida de comunicaciones personales, ayuda a contextualizar la colección dentro del legado del autor y a comenzar a generar una conciencia sobre la entidad del tipo de material. Así sabemos que en origen la colección estudiada estaba destinada al colegio La Salle Santa María de Sóller y que tras su clausura llegó en 1962 al colegio La Salle de Paterna por petición expresa del Hermano León (H. Miguel Pérez, com. pers. in. litt., 2016).

Por lo que respecta al herbario del Museo La Salle de Paterna, en primer lugar, se ha establecido que el orden de los cajones en la vitrina no representa ninguna razón práctica, encontrándose por lo tanto desordenado $(\mathrm{H}$. Jesús Comín, com. pers., 20l6). En cuanto a la colección del H. Bianor propiamente dicha, aunque muy pocas manos son las que han tratado este herbario, se conoce la revisión que de los pliegos realizó el Hermano León, encargado del mantenimiento del museo desde 1960 hasta su desaparición (H.Jesús Comín, com. pers., 20 I6).A lo largo de esta revisión se elaboró el catálogo de la colección que el propio museo contiene y se crearon también las etiquetas de los paquetes con el desglose de las familias que los componen. Además, el propio Hermano León fue quien anotó la numeración de la camisa de cada pliego $-C l$-, siguiendo el mismo orden que la numeración del interior del pliego -C2- pero evitando los saltos o las repeticiones -bis-. Como consecuencia existen dos numeraciones, la externa o de la camisa, $\mathrm{Cl}$, creada por el $\mathrm{H}$. León y que llega hasta el número de pliego $12 \mathrm{I} 4$, y la original interna, C2, creada por Bianor y que finaliza en el número de pliego I6II. Este desfase en la numeración atiende a la diferencia generada por el vacío de los ejemplares cedidos por el propio Bianor a otras instituciones.

El resultado de la diversidad de familias, donde las que mayor número de taxones contienen son las asteráceas, con un II, I\%, seguido de las leguminosas, $10,0 \%$, y las gramíneas, $7,6 \%$, se corresponde con la abundancia relativa de estas familias en la flora 
ibérica, donde las asteráceas son la familia más representada, seguida de las gramíneas y las leguminosas (Morales \& Quintanar, 20I3). Estas similitudes en la composición florística de la colección del $\mathrm{H}$. Bianor, también se constatan con lo que se conoce hasta la fecha de la flora del archipiélago balear, donde estas tres familias son las de mayor peso según Rita \& Payeras (2006), si bien las cifras que estos autores presentan para el número total de taxones, I445, son sensiblemente superiores a los que manejan SÁEZ et al. (2013), I 302 taxones, para la isla de Mallorca, por lo que podrían haber ligeros cambios en la significación de las diferencias encontradas para los grupos taxonómicos.

El análisis de los lugares de recolección revela que el municipio más representado fue el de Sóller, al cual pertenecen más de la mitad de los pliegos de la colección. Esto se debe a que la residencia fija de Bianor desde enero de 1905 hasta diciembre de 1912 se halló en Sóller, por lo que su radio de acción se encontraba muy centralizado en esta localidad.

El periodo de máxima recolección abarca cuatro años, entre $|9| 0-1913$, tiempo durante el cual se recolecta más de $66 \%$ del material. Previamente, había herborizado, pero sus problemas de salud le impidieron la continuidad que hubiera deseado (RuBí \& MALAGARRIGA, 197I). La explicación al descenso en el número de muestras recogidas, tras el periodo culmen de su actividad, puede ser debido a la conjunción de dos circunstancias. La primera, a una intensa sequía que asoló la región durante los años 1913 y 19|4, comentada por el propio Bianor:"Los campos están secos por falta de lluvia y temo no poder hacer gran cosa en materia de herborización" (véase BIANOR, 1917). Y la segunda, su traslado en otoño de 1914 a Avignon (Francia), para ayudar como enfermero en un hospital de guerra. A partir de su regreso a Mallorca, su delicada salud no le permitió continuar con su labor recolectora (RUBi \& MALAGARRIGA, I 97I). Los meses más intensos de recolección se realizaron durante el periodo primaveral, sobre todo abril y mayo, coincidiendo con la época de floración de la mayoría de las angiospermas.

En cuanto al empleo de las diferentes etiquetas, la gran similitud entre ellas parece indicar que no son más que distintas versiones de un mismo modelo impreso en diferentes imprentas y que el uso de una u otra no está promovido más que por la disponibilidad de las mismas, en función de las aportaciones económicas que recibía, especialmente de Sennen (Rubí \& MalAGARRIGA, I 97I). Por otra parte, que más de la mitad de las especies contenidas en esta colección tengan un uso práctico, puede sustentar la idea del origen didáctico de la colección.

En cuanto a los pliegos más destacados, se prevé necesaria una revisión en mayor profundidad de la colección para aislar los ejemplares más interesantes. Aquí se apuntan tres isolectotipos en epónimos de su nombre, material de Bianor conservado en el Museo de La Salle de Paterna, de los nombres Filago bianorii, Chaenorhinum rubrifolium var. bianorii y Aristolochia bianorii. En este sentido, es necesario seguir profundizando más en el material de Bianor para poder conocer la existencia de especímenes relevantes desde el punto de vista nomenclatural, ya que pueden existir ejemplares duplicados de los que fueran utilizados por autores como, por ejemplo, Sennen y Knoche para la descripción de taxones nuevos a partir del material recolectado por Bianor en Mallorca.

Por último, comentar que, aunque esta colección no represente la totalidad del trabajo de su autor, si supone un notable reflejo de la actividad y proceder de Bianor en sus años centrales de herborización. Además, gracias tanto a esta colección como al estudio de la figura del $\mathrm{H}$. Bianor se puede comprender mejor una época histórica en la que coexistieron grandes botánicos como Sennen, Knoche, Pau o Font Quer. También desde una perspectiva florística esta colección puede ser útil para abordar comparaciones espaciales o temporales con otras herborizaciones (BROOKE, 2000).

BiBLIOGRAFÍA

Andrés-Sánchez, S., Monserrat Martínez-Ortega, M \& Rico, E. 20I6.Typifications and a new name in Filago (Gnaphalieae, Asteraceae). Phytotaxa 243: 28I-290.

BenEDí, C. I99I.Taxonomía de Chaenorhinum rubrifolium agg. (Scrophulariaceae) en el área mediterránea occidental. Collect. Bot. (Barcelona) 20:35-77.

BIANOR, F. I 910 -1920. Epistolario. Del archivo del Laboratorio Botánico F. Sennen, Barcelona.

BIANOR, F. I9I7. Plantes de Mallorca. Butlletí de I'Institució Catalana d'Història Natural I7: I 33- I 50.

Bridson, D. M. \& Forman, L. 1992. The Herbarium Handbook. Rev. ed. Kew, London U.K., Royal Botanic Gardens.

Brooke, M. DE L. 2000. Why museums matter. Trends in Ecology \& Evolution I5 (4): I 36-I 37.

Castroviejo, S. 1986. Aristolochia L. In: Castroviejo, S., Aedo, C., Cirujano, S., Laínz, M., Montserrat, P., Morales, R., Muñoz Garmendia, F., Navarro, C., Paiva, J. \& Soriano, C. Editores. Flora iberica I. Real Jardín Botánico, C.S.I.C., Madrid: 20I-205.

Castroviejo, S. (I986-20I2). Flora iberica I-8, I0-I5, I7-I8, 2 I. Real Jardín Botánico, CSIC, Madrid 
Colegio La Salle Paterna. 20I7a. http://www.lasallepaterna.es/quienes-somos/historia-del-centro-2/. [Consulta: I2/05/20I7].

Colegio La Salle Paterna, 20I7b. http://www.lasallepaterna.es/servicios/museo/. [Consulta: I2/05/2017].

Dalton, R. 2003. Natural history collections in crisis as funding is slashed. Nature 423: 575.

ERBEN M. 1989. Bemerkungen zur Taxonomie der Gattung Limonium V. Mitt. Bot. Staatssamml. München 28: $313-417$.

Erben, M. 1993. Limonium Mill. In: Castroviejo, S., Aedo, C., Cirujano, S., Laínz, M., Montserrat, P., Morales, R., Muñoz Garmendia, F., Navarro, C., Paiva, J. \& Soriano, C. Editores. Flora iberica 3. Real Jardín Botánico, C.S.I.C., Madrid: 2-143 .

FlanNery, M. C. 2012 . Flatter than a Pancake:Why Scanning Herbarium Sheets Shouldn't Make Them Disappear. Spontaneous Generations 6(I): 225-232.

Funk,V. 2003. 100 uses for an herbarium (well at least 72). ASPT Newsletter 17(2): I7-19.

Gálvez-Prada, F., Sañudo, B. J., Franco-Navarro, J. D. \& Serrano, J. P. 20I4. Digitalización del Herbario de D.Vicente Latorre y Pérez en el I.E.S. Padre Luis Coloma de Jerez de la Frontera. Boletín de la Real Sociedad Española de Historia Natural Sección Aula, Museos y Colecciones I: 47-55.

GBIF.ES [en línea]. Museo Hermano León. Nodo Nacional de Información sobre Biodiversidad. <http://www.gbif.es/ic_colecciones.php?ID_Coleccion=9700> [Consulta: 09-07-20 I6].

IBÁÑ̃EZ, N. 2006. Estudis sobre cinc herbaris històrics de l'Institut Botànic de Barcelona. Tesis doctoral. Departamento de Botánica, Facultad de Biología. Universidad de Barcelona, Barcelona.

JeNKINS, M. 2003. Prospects for biodiversity. Science 302(5648): I I 75-I I 77.

KNOCHE, H. 1922. Flora Balearica. Étude phytogéographique sur les îles Baléares. Vol. 2. Imp. Roumégous et Déhen, Montpellier.

LALOUETTE, J. 2004. Émile Combes, portrait d'un anticlérical. L'Histoire, 289.

La Salle Bonanova [en línea]. Museo Bonanova. < http://www.bonanova.lasalle.cat/index.php/ca/ serveis-3/museus> [Consulta: 06-09-2016].

LEUTE G.-H. 1970. Untersuchungen über den Verwandtschaftskreis der Gattung Ligusticum L. (Umbelliferae). 2. Teil. — Ann. Naturhist. Mus. Wien 74: 457-519.

McNeill J., Barrie F. R., Buck W. R., Demoulin V., Greuter W., HaWksworth D. L., Herendeen P. S., Knapp S., Marhold K., Prado J., Prud'homme van Reine W. F., Smith G. F., Wiersema J. H. \& TurLAND N. J. (ed.) 2012 : International Code of Nomenclature for algae, fungi, and plants (Melbourne Code) adopted by the Eighteenth International Botanical Congress Melbourne, Australia, July 20I I. - Regnum Veg. I54. Koeltz Scientific Books, Königstein, I-208 [plus Appendices II-VIII].

Morales R. \& QuintanaR, A. 2013. Algunos grupos y familias de plantas vasculares en España. In: MORALES, R. Coord. Las plantas silvestres en España. Colección divulgación, CSIC. Madrid.

NARDI, C.F. I 984. The genus Aristolochia L. (Aristolochiaceae) in Italy. Webbia 38: 22 I-300.

PAU, C. I 91 I. Sobre plantas mallorquinas. Butlletí de I'Institució Catalana d'Història Natural. I I: I619.

Peralta, I. E. 1992. Los herbarios. Su valor como colecciones activas. Multequina I: I89-192.

PYKE, G. H. \& EHRLICH, P. R. 20 I0. Biological collections and ecological / environmental research: a review, some observations and a look to the future. Biological Reviews 85(2): 247-266.

RITA, J. \& PAYERAS, T. 2006. Biodiversidad de las plantas vasculares de las Islas Baleares. Orsis 21 : $4 \mid-58$.

Rosselló, J.A. \& SÁEZ, LL. 2000. Index Balearicum: An annotated check-list of the vascular plants described from the Balearic Islands. Collect. Bot. (Barcelona) 25: 3-203.

Rouhan, G., Dorr, L. J., Gautier, L., Clerc, P., Muller, S. \& Gaudeul, M. 20I7. The time has come for Natural History Collections to claim co-authorship of research articles. Taxon. I-sep 2017: 3.

Rubí, S. \& Malagarriga, T. I 97I. H. Bianor educador y botánico. Ediciones San Pio X. Salamanca.

Sáez, Ll., Fraga, P. \& López-Alvarado, J. 2013 . The flora of the Balearic Islands. In: Cardona, E., Estaún, I., Comas, M. \& Fraga, P. Ed. Islands and plants: Preservation and undestanding of flora on Mediterranean islands. $2^{\text {nd }}$ Botanical Conference in Menorca. Proceedings and abstracts. Institut Menorquí d'Estudis, Consell Insular de Menorca. p. 91-I03.

Salgueiro Gonzales, F.J. 1998. Estudio sobre los herbarios históricos de la Universidad de Sevilla. Tesis doctoral. Universidad de Sevilla, Sevilla.

SCHMIDT, L. 2007. Digitization of Herbarium Specimens, a Collaborative Project. ACRL Thirteenth National Conference. Baltimore, Maryland.

SENNEN, F. I9I 3. Plantes d'Espagne: $3^{\text {a }}$ note. Bull. Géogr. Bot. 23: 33-5I.

SENNEN, F. 1936. Plantes d'Espagne. Diagnoses et comentaires. Troisième partie. Bol. Soc. Ibér. Ci. Nat. 35: 17-32.

Vollmar, A., MACKLIN, J.A. \& Ford, L. 20I0. Natural history specimen digitization: challenges and concerns. Biodiversity Informatics. 7: 93-II2.

WagenItZ, G. 1966. Die Sektion Evacopsis der Gattung Filago (Compositae-Inuleae) in westlichen Mittelmeergebiet. Berichten der Deutschen Botanischen Gesellschaft. 79 (7): 336-342.

Walther, G. R., Post, E., Convey, P., Menzel, A., Parmesan, C., Beebee,T. J. C., Fromentin, J. M., HoeghGULDBERG, O. \& BAIRLEIN, F. 2002. Ecological responses to recent climate change. Nature. 4I 6: 389-395. 
